\title{
SYSTEMS THINKING ABOUT PURPOSE
}

\author{
Gaye Lewis \\ University of South Australia \\ SA, Australia \\ Gaye.Lewis@unisa.edu.au
}

\begin{abstract}
This paper argues that in the context of human activity systems, the concept of purpose is critically important and that giving purpose a central role in the development and management of human activity systems can lead to more flexible, effective and autonomous systems. The systems thinking literature is reviewed in order to consolidate and assess current thinking about purpose. The importance of intrinsic purpose is highlighted. Implications for practice in terms of information systems design are illustrated by contrasting two different approaches to the design of knowledge management systems. An analysis of corporations as purposeful systems highlights some of the benefits of a purposeful systems approach. Directions for future research with a focus on purpose are suggested.
\end{abstract}

\section{INTRODUCTION}

Systems thinking research has long argued that the management of human activity systems requires a different management approach than that used to manage simple, mechanistic systems (eg. Checkland, 1994; Ackoff, 1999; Ulrich, 1983). Human activity systems are made up of people and one of the distinctive characteristics that separates people from other species and non-living objects is their ability to formulate and act in accordance with a purpose. The relevance of purpose to human activity systems has been mentioned before in the systems thinking literature, but often using different language and not always with purpose as the main focus of the research. This literature will be revisited with the explicit intention of synthesizing the thinking about purpose into one paper, which it is hoped will act to highlight a topic that is foundational to those who think about system design. Stebbing (1952) wrote about the importance of purpose in thinking and said "to think logically is to think relevantly to the purpose that initiated the thinking: all effective thinking is directed to an end." Elder and Paul (2001) argue that "Raising human goals and desires to the level of conscious realization is an important part of critical thinking". In order to help with the development of effective human activity systems, suitable for encouraging innovative and adaptive 'thinking' managers and employees, the concept of purpose and its application will be explored. More specifically, this paper will explore the argument that purpose is a key concept that must be incorporated into the development and management of human activity systems.

The importance of purpose has also been emphasised in the management literature. Bartlett and Ghoshal (1994) write that, "Senior managers of today's large enterprises must move beyond strategy, structure, and systems to a framework built on purpose, process, and people". Briskin (1999) writes that "Organizations facing a volatile market must address purpose as they attempt to undo much of what they once found to be successful.” The argument for incorporating purpose into management thinking has even stronger validity in the context of information systems development. As Bartlett and Ghoshal (1994) point out, the underlying problem with traditional approaches is in their objective "to create a management system that minimise(s) the idiosyncrasies of human behaviour". With information systems, the tendency to focus on the technology components of the system accentuates the problems inherent in traditional approaches. So, although this paper focuses on purpose in human activity systems in general, the conclusions are especially applicable to the design and development of information systems.

The paper begins with a discussion of the concept of purpose, and then develops a classification of different systems in terms of types of purpose. This classification is used to review the literature on systems thinking in order to critically evaluate the importance of purpose in the management and development of human activity systems. The main aim of the paper is to argue for the importance of purpose in the management and design of human activity systems by drawing on the systems thinking literature. Some implications for practice are suggested by analysing and assessing the purposefulness of some example information systems and corporations. The final section includes a summary and some potential directions for future research.

\section{PURPOSE}

The Oxford English Dictionary (1991) defines purpose as, "The object for which anything is done or made, or for which it exists; the result or effect intended or sought; end, aim”. In common language, the same word purpose - is attributed to inanimate objects and to humans - a clock's purpose is to tell the time in the same way that a human's purpose in setting the alarm is to wake up on time. For the analysis here, it is important to distinguish between these two different uses of the word purpose, as will be discussed further later in this section. Suffice it to say here that purpose can only be exhibited by human beings and represents a form of internal motivation - why people do what they do. Another important characteristic of humans that enables the formation of purpose is our ability to be self-reflective. It is in the process of reflection that we develop and become aware of our individual purposes. 
Aristotle (Strong, 2000) believed that to understand the existence of artificial (man-made) phenomena, four general principles (causes) must be explored. His description of the final cause is "the reason for the phenomenon's existence or that purpose for which it was created", which is consistent with the modern definition of purpose above. Aristotle's other causes are the material cause which represents the phenomenon's physical manifestation, the efficient cause which identifies the processes involved in producing the phenomenon and the formal cause which embodies the essence of the phenomena. These causes are concerned with what the phenomenon is and how it is made rather than exploring why it exists. Taking Aristotle's point that in order to understand a phenomenon it is critical to explore its purpose, the distinction between artificial and natural phenomena and their relation to purpose will be explored in detail later in this section.

Further support for the importance of purpose is evidenced by the way it is applied within the legal system. The degree to which intent and self-reflection can be established in a criminal act can have a profound influence on the severity of the resulting sentence. A verdict can range from manslaughter (no intent to kill) to second degree murder (intent to kill is not pre-meditated) to first degree murder (pre-meditated intent to kill). The harshest sentences correspond with the highest degree of self-reflection and purpose.

\section{Types of Purpose}

For the analysis in this paper, it is important to explicitly distinguish between two types of purpose - extrinsic and intrinsic. Extrinsic or ascribed purpose is the purpose of a system as seen by an observer or designer. A system with extrinsic purpose has been designed intentionally for fitness of purpose and is perceived to serve a purpose. 'Purposive' is the terminology often used to describe this type of purpose. Intrinsic purpose can only be attributed to systems involving people and represents the free will of the person/people within the system to act. 'Purposeful' is the terminology used to describe this type of purpose.

\begin{tabular}{l|l|c}
\multicolumn{1}{c|}{ Designed Systems } & \multicolumn{1}{|c}{ Natural Systems } & \\
\hline I. extrinsic + intrinsic purpose & II. intrinsic purpose & $\underline{\text { Human activity systems }}$ \\
\hline III. extrinsic purpose & IV. no purpose & $\underline{\text { Non-human systems }}$
\end{tabular}

Figure 1: System classes defined according to types of purpose.

Figure 1 characterises two dimensions of system classes according to whether they exhibit extrinsic and/or intrinsic purpose. Designed systems always have extrinsic purpose - they are designed and used for a reason. Human activity systems are the only type capable of exhibiting intrinsic purpose. A river is an example of a non-human, natural system with no purpose (quadrant IV). The argument that a river does have a purpose presupposes some form of designer and, since this paper is only concerned with improving the design of manmade systems, the river and other natural, non-human systems can be classified as having no purpose. A person or a family are both examples of human, natural systems with intrinsic purpose (quadrant II). An alarm clock is an example of a designed, non-human system which therefore has extrinsic purpose only (quadrant III). An information system or a football team are both examples of designed, human activity systems potentially exhibiting both extrinsic and intrinsic purpose (quadrant I). Figure 1 will be used to review some of the literature on systems thinking in reference to purpose. The focus in this paper is on designed, human activity systems - quadrant I. Management thinking as applied to designed human activity systems, such as a corporation or an information system, can be enhanced if it gives a central role to both extrinsic and intrinsic purpose. Potential enhancements are a result of focussing on this uniquely human aspect of human activity systems and include increased understanding, flexibility and motivation.

\section{Observer's Purpose}

Before reviewing the systems thinking literature in terms of intrinsic and extrinsic purpose, the concept of the observer's purpose in systems thinking will be described. The observer's purpose is the starting point for using systems concepts to describe an external reality, and an understanding of observer purpose is required in order to interpret systems thinking literature in terms of purpose. Based on his or her particular purpose (which may be to describe, use or design something), an observer will define the entities that make up the system, describe the relationships between the entities and so delineate the system's boundary with the external environment. Jordan's (1968) analogy of "recognising various different figures and backgrounds, depending upon, among other things (our) interests" provides a visual image of this concept. With physical systems such as an alarm clock, it can be difficult to separate the external reality from our system conception of it. With abstract systems 
such as a political system, it is more readily apparent that our conception of the system is the basis for its existence.

Delving into the systems concept in more detail, Checkland (1981) differentiates between two approaches for describing or analysing a system. The 'black box' approach identifies inputs and outputs that cross the boundary between the system and its external environment requiring a description of the transformations which must occur within the system to produce the outputs from the inputs. The second approach describes the internal state changes of the system as a result of inputs from the environment. The first approach looks from the outside in, whereas the second approach looks from the inside out. With human activity systems, the second approach provides more opportunities for the description and development of intrinsic purpose - the purposes of the people within the system.

\section{Extrinsic Purpose}

This section will explore the concept of extrinsic purpose as referenced by the systems thinking literature. Although the terminology may be inconsistent, several authors have looked at the concept of extrinsic purpose as defined in the previous section. In general, the authors referred to in this section have focussed on extrinsic purpose only and not considered intrinsic purpose. A richer, more comprehensive conceptualisation of systems can be developed with consideration of both types of purpose.

Rosenblueth and Wiener (1950) present an in-depth discussion of purposeful vs. non-purposeful behaviour. They argue that "if the term purpose is to have any significance in science, it must be recognizable from the nature of the act, not from the study of or from any speculation on the structure and nature of the acting object". In accordance with their argument, they only consider extrinsic purpose, and account for intrinsic control mechanisms without considering intrinsic motivation, which they would consider to be part of the structure or nature of the acting object. However, intrinsic motivation or purpose is also recognisable in the ability of purposeful 'objects' to change their actions even in a stable environment. The approach in this paper differs from theirs in that intrinsic motivation is considered critically important. Another difference in approach relates to the method of study. Their approach to scientific study is similar and limited to Checkland's 'black box approach' whereas Checkland's second approach offers more opportunities for the study of intrinsic motivation.

Dennett (1997) presents an argument for not differentiating between intrinsic and extrinsic purpose. His "intentional stance" for describing entities is similar to Rosenblueth and Wiener's approach to studying the nature of acts rather than the structure of an object. My interpretation of his argument is that since we are made up of parts and have evolved from parts with no intrinsic purpose, it is conceivable that we could design robots (once again made of parts with no intrinsic purpose) that would in effect evolve and display behaviour as purposeful as ours. This paper assumes that there is a fundamental difference between free will or intrinsic purpose and extrinsic purpose. In any case, the line of reasoning taken by Dennett is not relevant here. Whether or not 'purposeful' robots can be designed does not affect the discussion of purposeful people and groups of people in this paper.

\begin{tabular}{lll} 
Cell & \multicolumn{1}{c}{ Characteristics } & \multicolumn{1}{c}{ Example } \\
\hline 1 & Structural, purposive, mechanical & A road network \\
2 & Structural, purposive, organismic & A suspension bridge \\
3 & Structural, non-purposive, mechanical & A mountain range \\
4 & Structural, non-purposive, organismic & A bubble \\
5 & Functional, purposive, mechanical & A production line \\
6 & Functional, purposive, organismic & Living organisms \\
7 & Functional, non-purposive, mechanical & Changing water flow \\
8 & Functional, non-purposive, organismic & The space-time continuum
\end{tabular}

Figure 2: Jordan's (1968) system classification.

Jordan (1968) uses three different characteristics to classify systems. He proposes that systems differ importantly in their rate of change (static or dynamic), purpose (purposive or non-purposive) and connectivity (sparse/mechanical or dense/organismic). Eight system classes (cells) are defined by using all possible combinations of the three characteristics, as illustrated in Figure 2.

Jordan only considers extrinsic purpose (purposiveness) and so cells with the purposive characteristic map into the category of designed systems and cells that are non-purposive map into the natural systems category of Figure 1 as diagrammed in Figure 3. Since there is no consideration of intrinsic purpose, the difference between human and non-human systems is not relevant, and Jordan's classification does not specifically address the key area of interest in this paper - the purposefulness of human activity systems. 


\begin{tabular}{|c|c|c|}
\hline Designed Systems & Natural Systems & \\
\hline $\begin{array}{l}\text { I. \& III. } \\
\text { Cells 1,2,5,6 }\end{array}$ & $\begin{array}{l}\text { II. \& IV. } \\
\text { Cells 3,4,7,8 }\end{array}$ & $\frac{\text { Human activity systems \& }}{\text { Non-human systems }}$ \\
\hline
\end{tabular}

Figure 3: Jordan's systems taxonomy mapped onto Figure 1.

\section{Intrinsic Purpose}

Ackoff and Emery's (1972) definition of a purposeful system is "one that can change its goals in constant environmental conditions; it selects goals as well as the means by which to pursue them. It thus displays will. Human beings are the most familiar examples of such systems". This definition is consistent with the human designed and natural systems in Figure 1 (quadrants I and II). However, their approach to the study of purposeful systems is more in line with Rosenblueth and Wiener's tactic in that it studies purpose by analysing the nature of acts or the behaviour of the system. Their assessment of purposeful systems attempts to define an objective, quantifiable account of purposeful behaviour from an outsider's point of view - Checkland's 'black box' approach. The approach used by Ulrich (1983) (described in a later section) asks questions about the system's intentionality and self-reflectiveness which is more in line with Checkland's second approach and more appropriate to the study of systems with intrinsic purpose.

Ackoff (1999) develops a classification of systems where "the critical classifying variable is purpose." His classification consists of a hierarchy of four system types - deterministic, animated, social and ecological and he differentiates the types based on whether the parts and/or the whole of the system are purposeful. Deterministic systems such as alarm clocks are not purposeful and do not have purposeful parts. Animated systems such as people are purposeful, but their parts are not. Social systems are purposeful and so are their parts. Ecological systems are not purposeful, but their parts are. Ackoff is only concerned with intrinsic purpose, and so makes no distinction between designed and natural systems. His system classification maps to Figure 1 as illustrated in Figure 4.

Ackoff then describes the progression of thinking about organisations originally as deterministic systems then animated systems and now as social systems. As deterministic systems, the main purpose of an organisation was to make a profit and no other purposes were considered important. As an animated system, the main purpose of the enterprise became one of survival, but the parts of the system (the employees) were still not considered purposeful. He emphasises that a systemic transformation from an animated system to a social system (where both the whole and the parts are purposeful) is required "if an enterprise is to be successful in the current environment which is characterized by an increasing rate of change, interdependence, complexity, production, and dependence on knowledge and information.” Moving from an animated system to a social system in terms of Figure 1 involves moving from thinking in terms of non-human systems (Quadrant III) to human activity systems (Quadrant I) with the main difference being the incorporation of the intrinsic purposes of employees.

\begin{tabular}{|c|c|}
\hline Designed \& Natural Systems & \\
\hline $\begin{array}{l}\text { I. \& II. } \\
\text { Ecological systems } \\
\text { Social systems } \\
\end{array}$ & Human activity systems \\
\hline $\begin{array}{l}\text { III. \& IV. } \\
\text { Animated systems } \\
\text { Deterministic systems }\end{array}$ & $\underline{\text { Non-human systems }}$ \\
\hline
\end{tabular}

Figure 4: Ackoff's (1999) system classification mapped onto Figure 1.

Boulding (1956) developed a classification of system types based on an intuitive judgement of the degree of complexity. His types range from structures and frameworks at level 1 to transcendental systems at level 9 (refer to Figure 5) with new characteristics emerging at each level. Intrinsic purpose or motivation would be considered an emergent property of level 7 systems, which are represented by man. Some might argue that it also exists at level 6 (animals), but that discussion is not relevant here. Self-consciousness and self-reflection are two characteristics that also emerge at level 7. These characteristics of purposefulness, self-consciousness and self-reflection would then also exist at level 8 and level 9 (socio-cultural and transcendental systems). 


\begin{tabular}{llll} 
Level & \multicolumn{1}{c}{ Type of System } & Example \\
\hline 1 & Structures, Frameworks & bridge & \\
2 & Clock-works & & clock \\
thermostat & & flames \\
3 & Control mechanisms & & \\
4 & Open systems & plants & \\
5 & Lower organisms & birds & \multicolumn{2}{c}{ human beings } \\
6 & Animals & families \\
7 & Man & ? &
\end{tabular}

Figure 5: Boulding's (1956) system classification.

n terms of Figure 1, Boulding's classification makes no distinction between natural and designed systems, since both can exhibit varying degrees of complexity and that is his main concern. Since purpose (intrinsic purpose) emerges as a characteristic in systems at level 7 and above, Boulding's levels 1 through 8 can be mapped onto Figure 1 as illustrated in Figure 6. Level 9 (transcendental systems) appears outside of the Figure 1 classification.

Designed \& Natural Systems

\begin{tabular}{l|l}
\hline $\begin{array}{l}\text { I. \& II. } \\
\text { Levels } 7 \text { \& 8. }\end{array}$ & Human activity systems \\
\hline $\begin{array}{l}\text { III. \& IV. } \\
\text { Levels } 1-6 .\end{array}$ & $\underline{\text { Non-human systems }}$
\end{tabular}

Figure 6: Boulding's system levels as mapped onto the classes of Figure 1.

Boulding argues that any problem that exhibits the characteristics of a certain level cannot be solved with a lower level system. One of the arguments of this paper is that approaches such as those used in MBO (Management by Objectives) programs and goal-oriented systems are not capable of solving highly complex management problems, because they are situated somewhere within levels 4-6 and the problems they are trying to solve are level 8 problems in Boulding's classification. Purposefulness, self-consciousness and self-reflection of systems are not considered to be critical characteristics in these goal-oriented approaches.

Checkland (1981) defines a set of systems classes intended to be helpful in developing research approaches to management problems - not simply in classifying different types of systems. His classes are as follows:

- $\quad$ Natural physical systems

- $\quad$ Designed physical systems

- $\quad$ Designed abstract systems

- Human activity systems

- Transcendental systems

Checkland's system types map to those of Figure 1 as illustrated in Figure 7. Transcendental systems are once again outside of the classification. Checkland does not differentiate between natural human and natural nonhuman systems.

\begin{tabular}{l|l|l}
\multicolumn{1}{c|}{ Designed Systems } & \multicolumn{1}{|c}{ Natural Systems } \\
I. & II. & Human activity systems \\
Human activity systems & Natural physical systems & Non-human systems \\
\hline $\begin{array}{l}\text { III. } \\
\text { Designed, physical systems } \\
\text { Designed, abstract systems }\end{array}$ & IV. &
\end{tabular}

Figure 7: Checkland's (1981) system types mapped onto Figure 1.

Checkland defines human activity systems as activities ordered in wholes as a result of some underlying purpose or mission. An important realisation (Checkland, 1994) is that "all real-world problem situations are characterized by the fact that they reveal human beings seeking or wishing to take purposeful action”, which once again supports the incorporation of purpose into the management and design of human activity systems. He also states that the perception of human activity systems is often emphasised by the existence of other 
designed systems. In the case of information systems, the activities are emphasised by the technology that supports them. Checkland stresses that it is important to separate the two but doesn't elaborate. With information systems, the focus often tends to be the technology and separating the two systems encourages more appreciation for the human aspects of information systems, including purpose.

Ulrich (1983) developed a purposeful systems paradigm as a conceptual framework to encourage designers of purposeful systems to be social planners rather than tool designers. Ulrich's definition of a purposeful system is as follows: "We designate a system $\mathrm{S}$ a purposeful system if $\mathrm{S}$ if self-reflective with respect to its own normative implications, seen from the point of view not only of the involved but also the affected, and if $S$ has at least partial autonomy in determining its client, its purposes, etc. "Partial autonomy" precludes the possibility that a system is purely extrinsically motivated; it means that the system can exercise its own will in choosing its goals.”

Ulrich goes on to reason that since only humans are self-reflective and autonomous, purposeful systems are made up of groups of individuals where some of their purposes are convergent or interdependent. The task of the purposeful designer is then to design for the purposeful individuals who make up the system i.e. enhance and facilitate critical reflection and allow for intrinsic motivation within the system. Purposeful system design is about the design of (for) social systems rather than the design of tools. Ulrich's concern is with the design of systems involving people, represented by Quadrant I in Figure 1.

Ulrich then provides a taxonomy for categorising a system's purposefulness in terms of the three basic kinds of problem-solving processes that a system must perform - Inquiry, Action and Valuation. For each of the processes the degree of intrinsic motivation and opportunity for critical reflection should be examined to assess the system's achievement of purposefulness. Inquiry assesses whether the system produces meaningful knowledge (with respect to its purpose). Action assesses how the system uses this knowledge purposefully. Valuation measures the systems' ability to responsibly evaluate the effects it is having on clients and anyone else who might be affected through the production and use of its knowledge. These categories add another dimension to Quadrant I of Figure 1 and can be used to assess the purposefulness of designed human activity systems.

This completes the section of the paper reviewing systems thinking literature related to purpose. Support has been drawn from the literature for the argument that both extrinsic and intrinsic purpose should be considered critically important in the management and design of human activity systems. The next section will look at purpose within specific contexts by using Ulrich's taxonomy to assess the purposefulness of information systems and corporations.

\section{IMPLICATIONS FOR PRACTICE}

\section{Purposeful Information Systems}

As an illustration of the application of Ulrich's paradigm, knowledge management systems as classified by Alavi (2000) will be analysed. Alavi defines a knowledge management system (KMS) as "an IT-based system developed to support and enhance the primary organizational knowledge management processes of knowledge generation, knowledge codification, and knowledge transfer". Two underlying models of KMSs are described "(1) the repository model aims at codification of knowledge" and "(2) the network model aims at using the power of information and communication technologies to support the flow of knowledge in organizational settings and among networks of individuals”.

Using Ulrich's assessment approach, we can first ask whether either of these types of systems are purposeful inquiring systems, i.e. do they produce meaningful knowledge with respect to their purpose, where purpose as defined above is to support and enhance organizational knowledge management processes. Looking first at the repository model, it does not produce any knowledge - it is only concerned with codifying or collecting knowledge - and so cannot be considered a purposeful inquiring system. The network model, however, does potentially allow for the production of knowledge by facilitating communication among individuals.

To evaluate whether each type of KMS is a purposeful action system, the question to ask is how the system makes purposeful use of the knowledge produced. Since the repository model is not concerned with producing knowledge, but only with storing and retrieving knowledge, this question does not apply. The network model does provide the opportunity for purposeful use of knowledge produced, but this can only be evaluated in the context of a specific system. Alavi provides an example of a network model KMS at British Petroleum where the knowledge produced by the system was used to quickly diagnose and efficiently solve an equipment problem experienced by a mobile drilling ship on the North Sea.

Finally, a purposeful valuation system is able to gauge the effects that knowledge production and use have on stakeholders. Since the repository KMS model does not produce any knowledge, the question once again is not applicable. KMSs that follow the network model provide the potential for increasing awareness of possible effects by stimulating discussion and facilitating communication among stakeholders. Whether or not this potential is realised depends on the specific KMS and the particular context in which it is being used.

In summary, the repository model of KMS is more about tool design than social system design, whereas the network model provides opportunities for social system design. The repository model exhibits only extrinsic 
purpose - it is developed to serve a purpose. The network model incorporates both extrinsic and intrinsic purpose - it is developed to serve a purpose and to enhance and facilitate critical reflection by the people within the system. There are opportunities for the individuals within the system to creatively develop ways of achieving the extrinsic purpose. The network model represents a more flexible, autonomous paradigm with more capabilities for adapting to complex, dynamic environments.

\section{Purposeful Corporations}

In order to assess the purposefulness of a corporation, it is important to realise that the corporate vision or mission statement represents the extrinsic purpose of the corporation. Intrinsic purpose is manifested in the desires and actions of the employees, which cannot be directly controlled. However, purposeful corporations can be facilitated by defining and operationalising an appropriate corporate purpose. The corporate purpose defines why the corporation exists and, if it is value laden, it can attract and retain employees with similar values. This alignment of intrinsic and extrinsic purpose can lead to increased motivation and commitment of employees. Defining the corporate purpose in broad terms and encouraging employee articulation of and action towards specific goals that support the corporate purpose can lead to increased flexibility and more autonomous employees. Bartlett and Ghoshal (1994) cite several examples of recently successful companies whose success they attribute in large part to the emphasis placed on developing and implementing an appropriate corporate purpose. Using Ulrich's paradigm, these examples will be analysed to highlight how the development of purposeful corporations was facilitated.

- AT\&T developed a corporate purpose to become the world's best at bringing people together with the corresponding slogan 'anytime, anywhere'. Employees participated in strategy forums to develop ideas about how to achieve the stated purpose. This encouraged the production of meaningful knowlege with respect to the corporation's purpose, satisfying Ulrich's definition of a purposeful inquiry system.

- Komatsu's corporate purpose to become a total technology enterprise was embodied by the slogan 'growth, global, groupwide'. Management at all levels were encouraged to find and explore opportunities consistent with the corporate purpose - once again qualifying as a purposeful inquiry system. Komatsu also instituted a committee to look at the broad social contributions of the company which would classify it as a purposeful valuation system according to Ulrich.

- At $3 \mathrm{M}$, employees were encouraged to spend $15 \%$ of their time on bootleg projects - projects which represented original ideas of employees. This encouraged both the production and use of meaningful knowledge with respect to the corporation's purpose and would be considered a purposeful inquiry and action system according to Ulrich's definition.

- The Body Shop, with its commitment to environmental causes and Corning with its focus on producing world-class quality products both espouse values that employees can identify with and are willing to commit to. Alignment of intrinsic and extrinsic purpose is thus facilitated. Whether these corporations qualify as purposeful according to Ulrich's definition depends on how these values are operationalised within the corporations.

In the above examples, the adoption and interpretation of the corporate purpose by employees enabled the development of purposeful corporations, by increasing the alignment and contribution of intrinsic purpose. In some cases, these companies had moved from specific, value-free statements to the broad, value-laden purposes outlined above (Bartlett and Ghoshal, 1994). For example, Komatsu's previous strategy had been to catch up and surpass their major competitor - Caterpillar - and AT\&T's previous strategy had been phrased in very specific technical terms. A corporate purpose which states what the corporation does only leaves room for employees to decide how to achieve goals. A corporate purpose which defines why the corporation exists leaves room for employees to decide both what can be done to achieve the purpose and how to go about it. This leads to the idea that well-defined goals represent a specific instantiation of objectives that relate to an overall purpose. The crucial benefit that arises out of this realisation is flexibility. Many different goals can help to achieve the same purpose. This difference of including both why and what becomes increasingly important as management tasks become more complex and less well defined/quantifiable and as more of the work force is represented by autonomous decision-making managers.

There is a significant amount of research centred around Locke's theory of using goals to increase employee motivation and performance. A review of this research was conducted by Latham and Yukl (1975). One of their main criticisms is that "Goals that are assigned to a person ... have an effect on behaviour only to the degree that they are consciously accepted by the person." They proceed to point out that the "greatest deficiency of Locke's theory is the failure to specify the determinants of goal acceptance and goal commitment". This commitment versus compliance to goals evolves from the added value of purpose. While goals relate to an external object or state to be realised, purpose represents an internal desire. Goals must be aligned with intrinsic purpose in order to maximise motivation/performance improvements.

Fitzhardinge (1997), in an environmental context, highlights the difference between goals and values where he says values are related to purposeful activity. "Goals are desired ends or states, some are self-sufficient and 
others instrumental to gaining more desired ends. Their main defining feature is that they can be uniquely satisfied. Values, however, are more personal property, and a value system is said to predetermine behaviour in various areas." Once again the inflexibility of goals and the potential lack of internalisation are emphasised. Angell (1990) states that "Environments are continuously changing, and to be effective a system must be capable of a variety of responses to match those changes in the environment (Ashby's Law of Requisite Variety)". Thinking in terms of purpose helps to enable this type of flexibility - specific goals and objectives can be adapted to changing environments and clear, consistent purpose can be used to drive their selection.

\section{CONCLUSION}

This paper has argued that both extrinsic and intrinsic purpose are key concepts that should play a central role in the development and management of human activity systems. Definitions for extrinsic and intrinsic purpose have been presented and a classification of system types in terms of purpose outlined. This classification was then used to review the systems thinking literature in terms of purpose. Support for the importance of purpose in human activity systems was drawn from the systems thinking literature. Ackoff (1999) emphasises "that a systemic transformation from an animated system to a social system (where both the whole and the parts are purposeful) is required if an enterprise is to be successful in the current environment which is characterized by an increasing rate of change, interdependence, complexity, production, and dependence on knowledge and information." Boulding argues that any problem that exhibits the characteristics of a certain level cannot be solved with a lower level system. The properties of purposefulness, self-consciousness and self-reflection are required in order to deal with the high level of complexity of today's management problems. Checkland (1994) states that "all real-world problem situations are characterized by the fact that they reveal human beings seeking or wishing to take purposeful action”.

Different approaches for studying human activity systems were briefly discussed. Checkland describes two approaches - the 'black-box' approach which studies systems from the outside in and his second alternative with an emphasis on proceeding from the inside out. It was pointed out that the second alternative offers more opportunities for the study of intrinsic purpose. Accordingly, the literature, which takes a 'black-box' approach to the study of human activity systems, is not as rich or comprehensive in terms of dealing with purpose as literature which takes the second approach. Ulrich provides a practical approach for evaluating the purposefulness of human activity systems in line with Checkland's second approach.

Two different models of knowledge management systems were analysed to illustrate some of the implications for practice of incorporating both extrinsic and intrinsic purpose in information systems design. The analysis revealed that the model that incorporates both types of purpose has more potential for producing flexible systems that can creatively adapt to complex, dynamic environments. More detailed empirical analysis of information systems would help to validate the claims made in this paper about the benefits of purposeful systems design. Further exploration of the contexts in which purposeful systems design is most appropriate is another potential direction for future research.

Several examples were highlighted to illustrate how the definition and implementation of an appropriate corporate purpose (extrinsic purpose) could lead to more opportunities for aligning intrinsic purpose with corporate purpose, thereby increasing employee motivation and commitment. It was argued that 'thinking' managers are better able to creatively formulate alternatives and make decisions when guided by purpose than when carrying out specific goals. This section of the paper touched on some of the potential benefits of focussing on purpose rather than goals. Further development and substantiation of these ideas is a possible area for future research.

One final potentially fruitful direction for future research will be mentioned here. The problem of alignment between corporate strategy and information systems strategy involves two types of human activity systems corporations and information systems. As argued in this paper, both systems can benefit from management thinking with a focus on purpose. The concentration on purpose in both systems could then be used as a focal point to allow for more flexibility and creativity in strategy formulation and alignment. Aligning purposes is a logical extension to focussing on purpose and it may provide a novel and insightful approach to research in the area of strategic information systems planning. 


\section{REFERENCES}

Ackoff, R.L., Emery, F.E. (1972) On Purposeful Systems, London: Tavistock and Chicago: Aldine-Atherton Ackoff, R.L. (1999) “Transformational Leadership”, Strategy and Leadership, 27(1), 20-25

Alavi, Maryam (2000) “Chapter 2 - Systems for Managing Organizational Knowledge,” in Framing the Domains of IT Management: Projecting the Future Through the Past, R.W. Zmud and M.F. Price (eds.), Pinnaflex Educational Resources Inc., Cincinnati, 15-28

Angell, I.A. (1990) “Systems Thinking About Information Systems and Strategies”, Journal of Information Technology, 5, 168-174

Bartlett, C. A. \& Ghoshal, S. (1994) “Changing the Role of Top Management: Beyond Strategy to Purpose”, Harvard Business Review, 72(6), 79-88.

Boulding, K. (1956) “General Systems Theory - The Skeleton of Science”, Management Science, 2(3), 197208

Briskin, A. (1999) “In Pursuit of Purpose”, Journal for Quality and Participation, 22(1), 6-12.

Checkland, P.B. (1981) Systems Thinking, Systems Practice, John Wiley and Sons Ltd.

Checkland, P.B. (1994) “Systems Theory and Management Thinking”, American Behavioral Scientist, 38(1), 75-89

Dennett, D.C. (1997) Kinds of Minds - The Origins of Consciousness, London: Phoenix

Elder, L. \& Paul, R. (2001) “Critical Thinking: Thinking to Some Purpose”, Journal of Developmental Education, 25(1), 40-41.

Fitzhardinge, G. (1997) “A Sense of Knowing, a Sense of Caring, a Sense of Place...”, 'Reading the Land' Workshop Proceedings, Canberra

Jordan, N. (1968) Themes in Speculative Psychology, London: Tavistock

Krebs, W.A. (1997) Collins Compact Australian Dictionary, Harper Collins Publishers

Latham, G.P., Yukl, G.A. (1975) “A Review of Research on the Application of Goal Setting in Organizations”, Academy of Management Journal, 18(4), 824-845

Murray, J.A.H., Bradley, H., Craigie, W.A., Onions, C.T., Burchfield, R.W. (eds.) (1991) The Oxford English Dictionary, Second Edition, Volume XII, Oxford University Press, Oxford, 878

Rosenblueth, A., Wiener, N. (1950) “Purposeful and Non-purposeful Behavior”, Philosophy of Science, 17, 318-326.

Stebbing, S. (1952) Thinking to Some Purpose, London: Penguin Books

Strong, K.C. (2000) “A Voice From the Past: Aristotle on the Mission of the Firm”, Business and Professional Ethics Journal, 19(2), 83-94

Ulrich, W. (1983) Critical Heuristics of Social Planning, John Wiley and Sons Ltd 